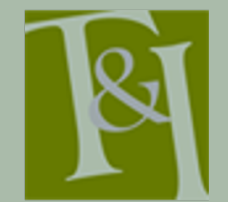

The International Journal for Translation \& Interpreting Research trans-int.org

\title{
Integrating collaborative localization into professional translator training
}

\author{
María del Mar Sánchez Ramos \\ University of Alcalá, Spain \\ mar.sanchezr@uah.es
}

DOI: 10.12807/ti.113201.2021.a03

\begin{abstract}
Non-professional translation (NPT) has attracted increasing attention in translation studies in recent years. As a consequence, translator training needs to take NPT into account in the translation curriculum. In this article I report the findings of an exploratory study conducted to implement and evaluate an online collaborative localization project as an example of NPT. Drawing on quantitative and qualitative methods, the findings show that the trainees had a positive attitude towards NPT practices and were highly satisfied with the inclusion of NPT in the localization curriculum.
\end{abstract}

Keywords: non-professional translation (NPT); crowdsourcing; online collaborative translation; localization.

\section{Introduction}

The coming of the internet and the subsequent emergence of social networks represent a new departure in communication between clients and translation services providers, but also in how information is exchanged between them. In this context, new translation scenarios have started to emerge, including translation crowdsourcing and online collaborative translation as examples of non-professional translation (NPT) ${ }^{1}$ (Jiménez Crespo, 2019). Declerq (2014, p. 46) refers to translation crowdsourcing as "the outsourcing of a task (or several tasks at the same time) to an undefined, generally large, group of people or community, mutually connected through an e-medium." Closely related is the concept of online collaborative translation practices, which Jiménez Crespo (2019, p. 304) recently defined as: "cases in which self-organized translation communities with specific interests or goals initiate and produce their own translation projects." It should be noted that the main difference lies in the initiator; for translation crowdsourcing, it is a company or institution, whereas for online collaborative translation, it is a group of volunteers who, motivated by a range of factors, unite in a primary goal of enabling other communities of users to access content in their own language: "the relationship established in

\footnotetext{
${ }^{1}$ Jiménez Crespo (2019) provides a detailed description of the main concepts related to NPT, such as crowdsourcing, online collaborative translation, fansubbing or activist/humanitarian translation. For the purpose of this study, I will focus mainly on crowdsourcing and online collaborative translation.
} 
crowdsourcing is of a vertical and hierarchical nature, whereas the norm for collaborative translations is a horizontal relationship, with processes established between equal peers" (Sánchez Ramos, 2018, p. 277).

Technological advances, therefore, have allowed volunteer translators from around the globe to gather in online communities and generate multilingual content. This form of translation, which is engaged in voluntarily, is particularly important for humanitarian work and emergency situations due to the fact that it enables communities to quickly access vital information and knowledge. In terms of localization, an activity defined by Schäler (2011, p. $157)$ as "the linguistic and cultural adaptation of digital content to the requirements and locale of a foreign market, and the provision of services and technologies for the management of multilingualism across the digital global information flow", collaborative localization tasks require knowledge of collaborative work platforms and specific formats (e.g., the Gettext system or portable object (.po) files, which are used for working on open-source software localization).

The developers of translation training programs are aware of the new social translation practices and there are examples of academic programs that exemplify the need to connect the academic work and social translation. Some initiatives have included online collaborative translation practices in the translator classroom (Al-Shehari, 2017; McDonough Dolmaya, 2012; Orrego Carmona, 2013, Sánchez Ramos, 2019). In fact, studies have been carried out to develop online collaborative training models, such as the Professional Approach to Translator Training (PATT) (Olvera Lobo et al., 2005), whose main goals are clearly related to crowdsourcing and collaborative initiatives (Jiménez Crespo, 2017). These innovative activities are grounded in "collaboration and immersion" in real or simulated working environments (Jiménez Crespo, 2017, p. 229), two key notions in modern approaches to translation teaching. The introduction of collaborative translation practices into translation classrooms also appears to be closely aligned with European Higher Education Area (EHEA) guidelines, which include the goal of developing competences, understood as skills, knowledge and attitudes oriented to learning processes. However, although there is a clear interest in NPT, collaborative translation practices involving free and open-source projects have not been widely researched in translation training contexts (Flanagan, 2016).

In view of the above, the module described in this article is aligned with the need to incorporate new practices, such as collaborative localization platforms, into the translation curriculum. The module was designed, implemented and evaluated as part of a course called Localization to provide an effective approach to the teaching of NPT.

\section{Is translation going 'social'?}

There is no doubt that we are in the throes of the so-called digital age, with ever more examples of advances that mark the unfolding of a socio-technological revolution. This digital age is also reflected in the creation of fully automated and interconnected linguistic practices. These practices, which entail a new perception of traditional patterns in communication exchange processes, clearly impinge on a reorganization of strategies for the exchange of information, and a change in teaching practices. In this context, translation practices are reorganized into digital paradigms of communication exchanges: collaborative work, social networks, market globalization, information access models, 
workflows, etc. Due to the development of these new practices, translation has widened in scope, focusing not only on relationships between languages but also on the adaptation of non-textual, semiotic and cultural elements. A good example is localization, which was conceived as the linguistic and cultural adaptation of a digital product to the demands of a certain market and regional standards, and which clearly exemplifies the multimodal nature of translation. Another example of digital translation practice is NPT, for instance through crowdsourcing and online collaborative translation. The expansion of NPTis a direct result of technological, social and cultural changes (McDonough Dolmaya \& Sánchez Ramos, 2019). The consolidation of Web 2.0 provides numerous opportunities for internet users to take part in different online activities, contributing to the idea of 'translation democratization' and also, recursively, shaping technology (O’ Hagan, 2016, p. 934).

The origins of the collaborative practices mentioned above can be found in crowdsourcing, an anglicism coined in an article published in Wired magazine by Jeff Howe (2006). Howe defined crowdsourcing as the outsourcing of a task previously carried out by a company's or institution's employees to a network of people. Within the context of translation studies, crowdsourcing refers to "a call by an organisation, institution, or collective to a large undefined community in the web to perform a translation task in a collaborative manner (Jiménez Crespo, 2017, p. 18). Such communities of professional and non-professionals translators work for a range of organizations and projects, mainly online and on a voluntary basis, i.e., without pursuing financial remuneration. Since this type of translation has a direct influence on translation in many different aspects (e.g., relevance for minority languages or explicit implications for translator trainer and professional translation practice), it is necessary for the translation discipline to engage in critical reflection.

Just as the popularity of translation as a social activity has grown in institutions, organizations and online communities, so too has interest within the discipline of translation studies (Desjardins et al., 2021). Studies to date have focused on a number of issues, such as motivational factors for volunteers (Cámara de la Fuente, 2015; Dombek, 2013, O’Brien \& Schäler, 2010; Olohan, 2014) and collaborative translation and translator training (Alonayq, 2021; AlShehari, 2017; McDonough Dolmaya, 2012; Orrego Carmona, 2013, Sánchez Ramos, 2019). Other studies focus on the attitudes of professionals to collaborative practices. For instance, Gough (2011) pointed to a general lack of knowledge about digital collaborative environments among translation professionals. Nearly a decade later, Flanagan (2016), reached the same conclusion based on her study of a corpus of 48 professional translators' blogs, and updated information on translator professionals' attitudes towards translation crowdsourcing. In the thematic analysis of the corpus, Flanagan (2016) suggested that translation crowdsourcing can enhance visibility of the translation profession but fails to enhance visibility of the professional translator; ethical concerns are raised regarding translator participation in nonprofit translation crowdsourcing, and the shifting of responsibility from the professional to the non-professional translator. It can be noted from Flanagan's (2016) conclusions that translation crowdsourcing raises the issue of the place of professional translation in NPT and the commitment and responsibility of those involved in NPT practices. Finally, regarding the quality of the end product of collaborative translation, the implications of crowdsourcing and online collaborative practices for translation quality cannot be overlooked, and this is a central issue in translation studies (Carreira Martínez \& Pérez Jiménez, 2011, 2018; Jiménez Crespo, 2011; Mitchell, 2015, Persaud \& O’Brien, 2017). 
Another pivotal issue in digital collaborative practices and translator training is the constructive interaction that develops among students, teamwork development, and the immersion in real or simulated working environments (Jiménez Crespo, 2017). Collaborative tasks are expected to provide scaffolding for other related activities, and it is through this collaborative scaffolding that learners can improve their linguistic and cognitive capacities (Aydim \& Yildiz, 2014). As previously mentioned, given that online collaborative practices are aligned with the main principles of the EHEA, introducing online collaborative practices into translator training is a powerful method for encouraging "cooperation, critical thinking, peer learning, and active participation towards an end product" (Aydim \& Yildiz, 2014, p. 162). This idea is also in line with the profession-oriented methodological approach known as situated learning of translation (Risku, 2002; González-Davies \& Enríquez-Raído, 2016; Gouadec, 2007), which "emphasises the idea that action is grounded in the concrete situation in which it occurs" (Prieto-Velasco \& Fuentes-Luque, 2016, p.77). In terms of teamwork development, we should not forget that this is a subskill of collaboration (Trilling \& Fadel (2009). Note also that teamwork is one of most in-demand skills in today's translation profession (Moghaddas \& Khoshsaligheh, 2019). Teamwork relies on "individuals working together in a cooperative environment to achieve common team goals through sharing knowledge and skills" (Tarricone \& Luca, 2002). Tarricone \& Luca (2002, p. $641)$ summarize the main attributes needed for effective teamwork as follows:

- Commitment to team success and shared goals. Team members need to be committed to the success of the team and their shared goals for the project $[\ldots]$.

- Interdependence. Team members need to create an environment where together they can contribute far more than as individuals [...].

- Interpersonal skills. These include the ability to discuss issues openly with team members, honesty, trustworthiness, supportiveness, respect and commitment to the team and to its individuals, as fostering a caring work environment is important to working effectively with other team members.

- Open communication and positive feedback. This requires actively listening to the concerns and needs of team members and valuing their contributions so as to create an effective work environment [...].

- Appropriate team composition. This is essential to the creation of a successful team, as members need to be fully aware of their specific roles and understand what is expected of them in terms of their contributions to the team and the project.

- Commitment to team processes, leadership and accountability. Team members need to be accountable for their contribution to the team and the project $[\ldots]$.

Projects or activities based on a teamwork setup boosts coordination and interpersonal and decision-making skills, and provide the opportunity for practicing interpersonal, conversational and critical thinking skills (Moghaddas \& Khoshsaligheh, 2019). However, working as part of a team needs to be learned. 


\section{Method}

The study described here follows an exploratory approach based on a case study designed to answer the following research questions:

- What is the attitude of trainee translators towards collaborative localization platforms?

- How can a collaborative localization platform module be implemented in localization teaching at university level?

In order to answer the research questions, a questionnaire (quantitative approach) was administered and completed in class at the end of an undergraduate translation classroom session, and this was followed by a qualitative approach involving semi-structured group interviews. The aim of both the quantitative and qualitative tools was to gain insight the efficiency of a module focused on NPT as part of the localization training program. As stated in the introduction, there have been some studies on NPT and translator training, but there is a dearth of research on NPT and open-source localization projects.

\subsection{Course description: participants, materials and procedure}

The study was conducted in the first half of the 2018-2019 academic year, within the elective Localization course (worth 8 ECTS credits), part of the undergraduate degree in Modern Languages and Translation (English-Spanish) at the University of Alcalá (Madrid, Spain). The duration of the course was one semester, covering the following modules:

- Week 1: Main issues in localization (3 hours)

- Week 2, 3, 4: Website localization and web accessibility (9 hours)

- Week 5,6 and 7: Software localization (9 hours)

- Week 8, 9: Mobile apps localization (6 hours)

- Week 10, 11, 12: Free open-source software localization, FOSS (9 hours)

- Week 13, 14, 15: Game localization (9 hours).

The main objective was twofold: firstly, to offer a teaching framework that would accommodate new models such as collaborative translation, and secondly, to promote critical attitudes, encouraging students to reflect on the diverse range of aspects related to NPT and initiate a debate on new translation models and their implications for the professional market.

Both the questionnaire and the semi-structured group interviews related to the module on Free open-source software localization, which was taught in 3hourly sessions in weeks 10,11 and 12 of the course. The study was rooted in the social constructivist theories proposed by Kiraly (2000, 2016), who argues in favour of project-based real translation work, such as tasks performed under situational approaches. His social constructivist theory promotes "teaching methods that foster responsibility, independence, and the ability to see alternatives" (Kiraly 2000, p. 33). Social constructivism attaches much importance to collaborative work, active learning, and authentic tasks and projects. The learning environments endorsed by social constructivist theories consist of collaborative contexts in which students can work on situations that resemble the professional reality. This fosters interaction with technologies and fulfilling the roles involved in professional translation, such as those of project managers, terminologists, reviewers, and so on. We can tenably argue that the 
social constructivist approach is tightly connected to the philosophy of the online collaborative translation training, where there is an "immersion in real or simulated working environments" (Jiménez Crespo, 2017, p. 229).

The sample of 20 undergraduate students was divided into five groups of four students each. Participants were familiar with the tools involved in software and website localization, and their specific formats and techniques used in localization processes. They had previously received localization training as part of the software and website localization modules included in the Localization course. Prior to taking part in the localization project described here, students had carried out different interactive and collaborative sessions covering the main theoretical concepts related to online collaborative practices (definitions, typology, organizations, actors involved, etc.) and technical issues. The final localization project consisted of using a collaborative localization platform called Zanata ${ }^{2}$, a web-based translation platform where different users (i.e., translators, software developers) can work together on different localization projects. The project covered translations for Android smartphone applications. Students could choose to translate online or could download the files assigned to the project (.po files) to work offline with the help of the CAT tool Virtaal ${ }^{3}$, a free open-source translation tool.

\subsection{Data collection}

As stated before, the data collection instruments were both quantitative (a questionnaire) and qualitative (semi-structured interviews). As Edley \& Litoselitti (2018) recommend, the questionnaire was designed using a 5-point Likert-type scale reflecting agreement or disagreement. Each statement was assigned a numerical value as follows: (1) Strongly disagree, (2) Disagree, (3) Neutral, (4) Agree, (5) Strongly agree. Before answering the questionnaire, students were told by the researcher, who was also the teacher, that their responses would be completely anonymous. Students confirmed they understood the activity as being part of a research project and accepted to participate. In order to ensure anonymity, the different questionnaires did not include any questions that could result in any potentially identifying information about participants.

The questionnaire consisted of a total of fifteen items covering questions about the collaborative platform, (items 1 to 4), knowledge consolidation via the localization project (items 5 and 6); students' perspectives on the incorporation of online collaborative practices in the localization training program (items 7 to 10), and perspectives on teamwork (items 11 to 15).

In terms of qualitative research tools, semi-structured focus group interviews were recorded and transcribed for content analysis (Bryman, 2012; Court, 2018). Focus groups are considered to be an efficient method for obtaining data from multiple participants (Edley \& Litoselitti, 2018) and they can also boost spontaneous responses and interaction among participants. Semistructured interviews, when administered to focus groups, require a protocol or interview guidelines in the form of a well-planned list of questions (Court, 2018). Permission to record the focus group interviews was also requested. To guide the group interviews, some questions were planned:

\footnotetext{
${ }^{2}$ Availabe at http://zanata.org

3 Available at https://virtaal.translatehouse.org
} 
- Could you comment in general terms on your experience in carrying out the FOSS project?

- Focusing on localization, what was the most important aspect of using an online collaborative translation platform?

- What difficulties did you encounter, if any?

- Did you consider teamwork to be an appropriate approach?

To ensure the validity and reliability of the data, all the interviews followed the proposed structure, took place in similar conditions, and had the same duration (approximately 40 minutes). Five interviews were conducted- one with each group. Each interview was recorded and transcribed, and then analysed to identify the main ideas in accordance with the content analysis approach (Bryman, 2012; Court, 2018).

\section{Results}

\subsection{Quantitative results}

In general terms, the data suggest that the participants had a positive attitude towards online collaborative practices, the platform used to launch the activity, and the project organization in teams.

Table 1 shows that participants had no major difficulties using the platform (item 1). Zanata was found to have a simple, intuitive interface that facilitated the editing of online segments and allowed files to be easily downloaded (item 2 ). Since the activity took place during the last segment of the training programme, the students already had the necessary technical background to independently manage different file formats and translation tools (item 3). The platform included translation memories (TMs) and glossaries, materials with which the participants were already familiar, however, as the translation activity was de-contextualised and the students were unaware of the origin of those materials, they did not attach great importance to them, as reflected also in the qualitative results reported below (item 4).

Table 1. 5 Likert-scale questionnaire and results for items 1-4

\begin{tabular}{|l|r|r|}
\hline & Mean (M) & $\begin{array}{r}\text { Standard } \\
\text { Deviation } \\
\text { (SD) }\end{array}$ \\
\hline 1.-The platform is user-friendly & 4.25 & 0.73 \\
\hline 2.-It is easy to edit the segments in Zanata & 4.44 & 0.51 \\
\hline 3.-It is easy to edit the segments in Virtaal & 4.50 & 0.51 \\
\hline $\begin{array}{l}\text { 4.-The translation memories and glossaries that Zanata } \\
\text { provides have been useful for carrying out the activity }\end{array}$ & & 0.48 \\
\hline
\end{tabular}

Table 2 shows participants' responses to questions on the linguistic and instrumental benefits of the project. It is clear from Table 2 that the lowest scores related to the acquisition of linguistic knowledge (item 5). The answers also reflected participants' development and consolidation of technical 
localization skills (item 6). For instance, one of the most challenging difficulties in software localization is to understand how variables work. These variables are "characters that are usually preceded by a percentage (\%) sign and replaced by another word, value or string at application run-time" (Esselink, 2000, p. 68). This is an important result, as incorporating NPT practices in localization training can help developing technical skills, as the qualitative data results confirmed.

Table 2. 5 Likert-scale questionnaire and results for items 5-6

\begin{tabular}{|l|r|r|}
\hline & Mean (M) & $\begin{array}{r}\text { Standard } \\
\text { Deviation } \\
\text { (SD) }\end{array}$ \\
\hline $\begin{array}{l}\text { 5.- The activity has improved the development of my linguistic } \\
\text { skills }\end{array}$ & 2.85 & 0.48 \\
\hline $\begin{array}{l}\text { 6.- The activity has improved my technological skills (i.e. } \\
\text { variables, file formats, management of TMs) }\end{array}$ & 4.75 & 0.36 \\
\hline
\end{tabular}

Table 3 shows that the participants were in favour of including this type of activity, and, by extension, collaborative translation, in the Localization course (item 7 and 8). Participants also highlighted the interest that the activity elicited in them towards online collaborative translation (item 9 and 10). These results also support the idea that there is a need for the localization training curriculum to be in line with any advances in the area of social translation.

Table 3. 5 Likert-scale questionnaire and results for items 7-10

\begin{tabular}{|l|r|r|}
\hline & Mean (M) & $\begin{array}{r}\text { Standard } \\
\text { Deviation } \\
\text { (SD) }\end{array}$ \\
\hline $\begin{array}{l}\text { 7.- The activity has increased my interest in the Localization } \\
\text { course }\end{array}$ & 4.55 & 0.50 \\
\hline $\begin{array}{l}\text { 8.- I think these activities should be part of the Localization } \\
\text { course }\end{array}$ & 4.60 & 0.50 \\
\hline $\begin{array}{l}\text { 9.- The activity relates to the general content of the Localization } \\
\text { course }\end{array}$ & 4.25 & 0.44 \\
\hline $\begin{array}{l}\text { 10.- The activity has increased my interest in online } \\
\text { collaborative translation }\end{array}$ & 4.05 & 0.64 \\
\hline
\end{tabular}

Finally, in terms of teamwork as the approach used for the project organization (Table 4), there were some initial difficulties when it came to working in teams (item 11), even though participants felt that teamwork allowed them to interact with and learn from their peers to improve their decision making. Teamwork also was reported to enhance participants' confidence in proposing solutions (item 12-14), and increased their sense of responsibility (item 15). 
Table 4. 5 Likert-scale questionnaire and results for items 11-15

\begin{tabular}{|l|r|r|}
\hline & Mean (M) & $\begin{array}{r}\text { Standard } \\
\text { Deviation (SD) }\end{array}$ \\
\hline 11.- Working with other students has not been a problem & 3.65 & 0.58 \\
\hline $\begin{array}{l}\text { 12.- I have been more involved in the activity as I have } \\
\text { been part of an online collaborative project }\end{array}$ & 4.10 & 0.36 \\
\hline $\begin{array}{l}\text { 13.- The activity has been helpful as I have been able to } \\
\text { interact with the other members of my group }\end{array}$ & 4.65 & 0.47 \\
\hline $\begin{array}{l}\text { 14.- I have learnt from the other students' answers } \\
\begin{array}{l}\text { 15.-Teamwork has increased my self-confidence and } \\
\text { problem-solving skills }\end{array}\end{array}$ & 4.15 & 0.83 \\
\hline
\end{tabular}

\subsection{Qualitative results}

Qualitative results derived from the semi-structured groups interviews were analysed and coded using a content analysis approach (Table 5), where data were observed and classified according to content categories (Bryman, 2012; Court, 2018). The following content categories became evident: advantages and disadvantages of online collaborative localization platforms, motivation related to NPT and teamwork organization.

Results showed that participants had a positive attitude towards the collaborative localization platform used for the FOSS project, although there were some individuals whose attitude was more cautious. Stated advantages included the opportunity to learn about online collaborative translation, which was previously mostly unknown to them as mentioned by the groups. Participants were able to appreciate the vast number of projects that are successfully localized into different languages thanks to these platforms (e.g., languages that were not familiar to them such as Azerbaijani, Amharic or Yoruba).

Very much in line with the social component of collaborative translation, the participants also echoed the commitment required by this type of project from the point of view of responsibility towards their community. Issues such as the satisfaction of seeing the project finished or being part of a team were mentioned by all the groups.

Participants also highlighted the benefits of working with file formats they knew (e.g. .po files), as this meant they could work quickly. They also mentioned that participating in a collaborative localization project encouraged them to share problems, such as appropriate terminology choices when deciding how to deal with variables.

In terms of the motivational aspect, as already pointed out by other scholars (McDonough Dolmaya 2012; O’Brien \& Schäler; 2011), the participants stressed that online collaboration had triggered their interest because they were able to learn localization processes such as file sharing and gain some professional experience with real projects. The positive findings reflected in the qualitative results largely overlap with the results from the quantitative data (questionnaire). 
Table 5. Content categories and content units ${ }^{4}$

\begin{tabular}{|l|l|}
\hline Content categories & Content units \\
\hline Advantages & $\begin{array}{l}\text { "I had no idea that there were so many } \\
\text { projects for so many languages. (...) Most } \\
\text { of them are not translated!" }\end{array}$ \\
"For me it was useful to work as part of a \\
team. I wasn't sure how to translate \\
variables in "Errors while loading \%ss" \\
"I was able to put into practice what I had \\
already learned in the localization class, \\
such as how to exchange .po files"
\end{tabular}

The participants also highlighted disadvantages of collaborative localization platforms. As an example, and as widely commented on in previous studies, ethical matters and output translation quality were also discussed (Flanagan, 2016). Some participants stated that the platform did not seem reliable at first and that they initially felt somewhat lost, but that this issue was resolved as their partners helped them. The participants did not think that it was ethical to perform 'free' localization tasks and expressed concern about the quality and final review for products after they were made available online. The participants also felt that it was sometimes difficult to decide on a final translation because of a lack of contextual information, and that, although the platform's translation suggestions and glossaries were helpful, the fact that it was not clear how reliable the source was undermined their confidence in them.

Participants generally expressed their satisfaction with the project, although some were reluctant to work in teams, as corroborated by the questionnaire findings. Initial team organisation was sometimes difficult in terms of the distribution of roles. However, and after analysing answers, the Free open-source software localization module contributed to improving communication, decision making and interpersonal interactions.

\footnotetext{
${ }^{4}$ Table 5 contains participants' unedited responses in English.
} 
With regard to knowledge acquisition, the participants considered that the activity helped them consolidate their knowledge of software localization files and processes and raised their awareness of these novel translation practices and this was also reflected in questionnaire responses. Participants confirmed their concern about getting involved in such open-source activities, even though they recognized that these provided translation practice opportunities. However, the participants agreed that the localization project was interesting and necessary. They also repeatedly mentioned that online collaborative practices should be part of the Localization course since they were connected to real translation projects that can be found on the Internet. All the groups explicitly mentioned that they had profited from the localization project as the content was new to them and considered that they would be able to apply what they had learnt in the near future. The analysis of the data also showed that the localization project generated an exceptional learning environment and was an excellent place for the exchange of different perspectives towards new translation practices.

\section{Conclusion}

Collaborative translation is an innovative activity that has arisen in response to new trends and needs in the production and dissemination of information, potentially making the translation process one that is more open and cooperative. The introduction of these collaborative models into translation classrooms seems closely aligned with guidelines from EHEA, where the objectives include the achieving of competences, which are being understood as sets of skills, knowledge and attitudes, all of which are very much oriented towards students' learning processes. Taking into account both the reality of new trends in collaborative translation and EHEA guidelines, this paper presents translator trainees' attitudes towards both the use of collaborative localization platforms and the introduction of these platforms as part of the Localization curriculum. The study employed a non-experimental descriptive methodology built upon quantitative and qualitative data-collection tools. In general, participants were favourably inclined towards the module and felt comfortable sharing their perspectives on online collaborative translation practices. In this sense, the use of authentic localization projects and working in teams was perceived by participants as an advantage. Students considered that sessions on emerging collaborative localization practices should continue to be part of the Localization curriculum. Working on a collaborative localization project also empowered students' motivation for both NPT practices and localization per se. Based on the results of the quantitative and qualitative components of the study, there is a convincing case for making a place for NPT in translation classroom. However, there are some challenges to be taken into account in terms of how to approach its teaching. The findings of the study suggest that the teamwork organization has been a valuable and appropriate tool to help introduce NPT as part of the localization curriculum, as it has enhanced students' confidence and sense of responsibility, among others. This paper, while by no means conclusive, also presents limitations that can be taken into account for future research. In this vein, quantitative and qualitative results offer a starting point for future studies on translation pedagogies and a contribution to the existing debate on crowdsourcing and collaborative translation. 


\section{References}

Aydin, Z., \& Yildiz, S. (2014). Using wikis to promote collaborative EFL writing. Language Learning and Technology, 18(1), 160-180.

Alonayq, A. (2021). Narrative Arabic translation online: another perspective on the motivations behind volunteerism in the translation sector. In R. Desjardins, C. Larsonneur, P. Lacour (Eds.), When translation goes digital. Case studies and critical reflections (pp. 91-119). New York: Palgrave Macmillan.

Al-Shehari, K. (2017). Collaborative learning: trainee translators tasked to translate Wikipedia entries from English into Arabic. The Interpreter and Translator Trainer, 11(4), 357-372.

Bryman, A. (2012). Social research methods. Oxford: Oxford University Press

Cámara de la Fuente, L. (2015). Motivation to collaboration in TED Open Translation Project. International Journal of Web-Based Communities, 11(2), 210-229.

Creswell, J. (2013). Research design: qualitative, quantitative, and mixed methods approaches. Thousand Oaks: Sage.

Court, D. (2018). Qualitative research and intercultural understanding. Conducting qualitative research in multicultural settings. London: Routledge.

Declerq, Ch. (2014). Crowd, cloud and automation in the translation education community. Cultus, 7, 37-56.

Desjardins, R., Larsonneur, C., \& Lacour, P. (2021). When translation goes digital. Case studies and critical reflections. New York: Palgrave Macmillan.

Dombek, M. (2014). A study into the motivation of internet users contributing: the case of Polish facebook user-translators. PhD Dissertation. Dublin City University.

Edley, N., \& Litoselitti, L. (2018). Critical perspectives on using interviews and focus groups. In L. Litoselitti (ed.), Research methods in linguistics (pp. 195-225). London: Bloomsbury.

European Higher Education Area (EHEA) guidelines. Retrieved May 24, 2019, from http://www.ehea.info

Flanagan, M. (2016). Cause for concern? Attitudes towards translation crowdsourcing in professional translators' blogs. Journal of Translation Studies, 25. Retrieved May 24, 2019 from https://www.jostrans.org/issue25/art_flanagan.php.

González-Davies, M., \& Enríquez-Raído, V. (2016). Situated learning in translator and interpreter training: bridging research and good practice. The Interpreter and Translator Trainer, 10 (1), 1-11.

Gouadec, D. (2007). Translation as a profession. Amsterdam/Philadelphia: John Benjamins Publishing.

Gough, J. (2011). An empirical study of professional translators' attitudes, use and awareness of Web 2.0 technologies, and implications for the adoption of emerging technologies and trends. Linguistica Antverpiensia, 10, 195-217.

Howe, J. (2006). Crowdsourcing: a definition. Wired blog network: Crowdsourcing, 14. Retrieved May 24, 2019, from http:/crowdsourcing.typepad.com/cs/2006/06/ crowdsourcing_a.html

Jiménez Crespo, M. A. (2017). Crowdsourcing and online collaborative translations. Amsterdam/Philadelphia: John Benjamins Publishing.

Jiménez Crespo, M. A. (2019). Localization research in translation studies. Expanding the limits or blurring the lines? In H. V. Dam, M. Nisbeth Brogger and K. Korning Zethsen (Eds.), Moving boundaries in translation studies (pp. 26-43). London: Routledge.

Jiménez Crespo, M. A. (2019). Technology and non-professional translation. In M. O'Hagan (ed.), The Routledge handbook of translation and technology (pp. 239255). London: Routledge.

Kiraly, D. (2000). A social constructivist approach to translator education: empowerment from theory to practice. Manchester: St. Jerome.

Kiraly, D. (2016). Authentic project work and pedagogical epistemologies: a question of competing or complementary worldviews? In D. Kiraly et al. (Eds), Towards authentic experiential learning in translator education (pp. 53-66). Göttingen: Mainz University Press. 
Moghaddas, M. \& Khoshsaligheh, M. (2019). Implementing project-based learning in a Persian translation class: a mixed-methods study. The Interpreter and Translator Trainer, 13(2), 190-209.

McDonough Dolmaya, J. (2012). Analyzing the crowdsourcing model and its impact on public perceptions of translation. The Translator, 18(2), 167-191.

McDonough Dolmaya, J. \& Sanchez Ramos, M. M. (2019). Characterizing online social translation. Translation Studies, 12(2), 129-138.

O’Brien, S. \& Schäler. R. (2010). Next generation translation and localization: users are taking care. Translating and the Computer, 32. Retrieved May 24, 2019, from http://doras.dcu.ie/16695/1/Paper_6.pdf

O’Hagan, M. (2016). Massively open translation: unpacking the relationship between technology and translation in the $21 \mathrm{stt}$ century. International Journal of Communication, 10, 929-946.

Olohan, M. (2014). Why do you translate? Motivation to volunteer and TED translation. Translation Studies, 7(1),17-33.

Olvera-Lobo, María D. et al. (2005). Translator training and modern market demands. Perspectives: Studies in Translatology, 12(2), 132-132.

Orrego-Carmona, D. (2013). Using non-professional subtitling platforms for translator training. Rivista Internazionale di Tecnica della Traduzione, 15, 129144.

Prieto-Velasco, J. A., \& Fuentes-Luque, A. (2016). A collaborative multimodal working environment for the development of instrumental and professional competences of student translators: an innovative teaching experience. The Interpreter and Translator Trainer, 10 (1), 76-91.

Risku, H. 2002. Situatedness in translation studies. Cognitive Systems Research 3, $523-$ 533.

Sánchez Ramos, M. M. (2018). Translation learning environment for the future: online collaborative practices. In B. Mousten, S. Vandepitte, E. Arnó \& B. Maylath (Eds), Multilingual writing and pedagogical cooperation in virtual learning environments (pp. 268-290). Pennsylvania: IGI-Global.

Sánchez Ramos, M. M. (2019). Mapping new translation practices into transaltion training. Promoting collaboration through through community based localization platforms. Babel, 65(5), 615-632.

Schäler, R. (2011). Localization. In M. Baker \& G. Saldanha (Eds.), Encyclopedia of translation studies (pp. 157-161). London: Routledge.

Suter, W. (2006). Introduction to educational research: A critical thinking approach. Thousand Oaks, California: Sage Publications, Inc.

Tarricone, P., \& Luca, J. (2002). Successful teamwork: q case study, in quality conversations. In Proceedings of the 25th HERDSA Annual Conference (pp 640646), Perth, Western Australia, 7-10 July. Retrieved September 2, 2019, from https://ro.ecu.edu.au/cgi/viewcontent.cgi?article=5007\&context=ecuworks

Trilling, B. \& Fadel, C. (2009). 21st century skills: Learning for life in our times. San Francisco, CA: John Wiley \& Sons.

Volkov, A. \& Volkov, M. (2015). Teamwork benefits in tertiary education: Student perceptions that lead to best practice assessment design. Education + Training, 57(3), 262-278. 